\title{
Direct on-chip DNA synthesis using electrochemically modified gold electrodes as solid support
}

\author{
Karen Levrie ${ }^{1,3^{*}}$, Karolien Jans ${ }^{1}$, Guy Schepers ${ }^{2}$, Rita $\operatorname{Vos}^{1}$, Pol Van Dorpe ${ }^{1,4}$, \\ Liesbet Lagae ${ }^{1,4}$, Chris Van Hoof ${ }^{1,3}$, Arthur Van Aerschot ${ }^{2}$, and Tim Stakenborg ${ }^{1}$ \\ ${ }^{1}$ imec, Kapeldreef 75, B-3001 Leuven, Belgium \\ ${ }^{2}$ KU Leuven, Medicinal Chemistry, Rega Institute, B-3000 Leuven, Belgium \\ ${ }^{3}$ KU Leuven, Dept. of Electrical Engineering (ESAT), B-3001 Leuven, Belgium \\ ${ }^{4}$ KU Leuven, Dept. of Physics and Astronomy, B-3001 Leuven, Belgium \\ *E-mail: karen.levrie@imec.be
}

DNA microarrays have propelled important advancements in the field of genomic research by enabling the monitoring of thousands of genes in parallel. The throughput can be increased even further by scaling down the microarray feature size. In this respect, microelectronics-based DNA arrays are promising as they can leverage semiconductor processing techniques with lithographic resolutions. We propose a method that enables the use of metal electrodes for de novo DNA synthesis without the need for an insulating support. By electrochemically functionalizing gold electrodes, these electrodes can act as solid support for phosphoramidite-based synthesis. The proposed method relies on the electrochemical reduction of diazonium salts, enabling site-specific incorporation of hydroxyl groups onto the metal electrodes. An automated DNA synthesizer was used to couple phosphoramidite moieties directly onto the $\mathrm{OH}$-modified electrodes to obtain the desired oligonucleotide sequence. Characterization was done via cyclic voltammetry and fluorescence microscopy. Our results present a valuable proof-of-concept for the integration of solid-phase DNA synthesis with microelectronics. 


\section{Introduction}

DNA microarrays represent one of the most powerful tools in genomic research. Enabling the analysis of thousands of genes at the same time, microarrays are used for a wide range of applications, including gene expression profiling, ${ }^{1-4)}$ single nucleotide polymorphism (SNP) detection, ${ }^{5,6)}$ pathogen detection ${ }^{7,8)}$ as well as target enrichment for next-generation sequencing. ${ }^{9,10)}$ A number of methods have been developed for the fabrication of microarrays. The different technologies fall into three main categories: spotting or microprinting techniques, photolithographic methods using masks or micromirrors, and electrochemical deprotection techniques using multi-electrode chips. ${ }^{11-13)}$ The latter category of electrochemically synthesized microarrays offers various advantages. The features of these microarrays correspond to the well-defined electrodes of the chip, so no additional patterning or alignment steps are needed. The individually addressable electrodes provide electrochemical stimuli to synthesize the different DNA probes in-situ on chip, hereby obviating the need for other equipment such as masks or mechanical spotters. Furthermore, with a multi-electrode chip as substrate, semiconductor technology can be leveraged to scale down the features sizes with lithographic resolution, hereby drastically improving feature density, throughput and cost.

DNA is often immobilized on glass or oxides, that can act as anchor layer for the coupling of the first DNA building block. ${ }^{14)}$ Instead of these insulating supports, electrode-based applications call for the attachment of DNA to conductive materials. The use of electrodes as suitable solid support for DNA probes requires an appropriate functionalization. To this end, deposition of a porous reaction layer was previously reported by Maurer et al. ${ }^{15,16)}$ As an alternative, we demonstrate a straightforward method for the functionalization of metallic electrodes. The proposed method relies on the electrochemical reduction of diazonium salts, known as electrografting. ${ }^{17-19)}$ Electrografting offers several advantages over alkanethiol self-assembled monolayers (SAMs), which are commonly used for surface functionalization. The reduction of diazonium salts results in a strong covalent binding to the electrode surface. Furthermore, functionalization via electrografting only takes a few seconds, while various thiol and silane chemistries typically take multiple hours. Another important advantage is the ability to site-specifically functionalize electrodes in an electroaddressable way. ${ }^{20)}$ As it has been shown to be an easy, fast and stable method for the functionalization of a variety of conductive materials, the popularity of the electrografting approach has immensely increased in the last decade. ${ }^{18,20,21)}$ Here, we demonstrate the electrografting of 4-aminophenethyl alcohol to introduce hydroxyl (-OH) groups onto gold 
electrodes. Oligonucleotides were synthesized directly on the modified electrodes via phosphoramidite-based chemistry, ${ }^{22,23)}$ using a commercial DNA synthesizer. The schematic of the proposed method is shown in Fig. 1. As a next step, we aim to implement electrochemical deprotection ${ }^{15)}$ to enable synthesis of a custom DNA sequence on each electrode of a multi-electrode chip.

Electrografting of electrodes as a solid support for on-chip DNA synthesis was previously reported in the form of an extended abstract. ${ }^{24)}$ In this paper, more detailed information is provided on the experimental methods. Further characterization of the electrografting of 4-aminophenethyl alcohol is included, as well as additional fluorescence data on the oligonucleotide synthesis.

\section{Experimental methods}

\subsection{Electrode functionalization and characterization}

The electrodes used in this work were fabricated via the evaporation of a $10 \mathrm{~nm}$ titanium (Ti) adhesion layer and a $100 \mathrm{~nm}$ gold $(\mathrm{Au})$ metal layer on top of a silicon ( $\mathrm{Si}$ ) substrate.

The electrochemical procedure to functionalize the gold electrodes was performed using an Autolab potentiostat ( $\mu$ AUTOLABIII/FRA2, Metrohm, Belgium) operated with Nova software (version 1.10). The functionalization was carried out using a standard three electrode configuration, with the gold electrode as working electrode, a flexible silver/silver chloride $(\mathrm{Ag} / \mathrm{AgCl})$ reference electrode and a platinum coil counter electrode. Prior to modification, the gold working electrode was thoroughly rinsed with acetone and IPA. After drying under a stream of nitrogen, the electrode was placed in a $\mathrm{UV} / \mathrm{O}_{3}$ chamber (UVO cleaner, Jelight Company, California) for $15 \mathrm{~min}$ to remove organic contamination.

2.1.1 Electrografting of 4-aminophenethyl alcohol. Hydroxyl groups were introduced onto the gold electrodes of ca. $1 \times 1 \mathrm{~cm}^{2}$ via electrografting of 4-aminophenethyl alcohol. To this end, $5 \mathrm{mM}$ of 4-aminophenethyl alcohol was dissolved in $20 \mathrm{~mL}$ of a $0.5 \mathrm{M}$ aqueous hydrochloric acid $(\mathrm{HCl})$ solution at $0{ }^{\circ} \mathrm{C}$. Prior to use, the solution was degassed for 10 min using nitrogen. While keeping the solution a $0{ }^{\circ} \mathrm{C}, 400 \mu \mathrm{L}$ of a $1.2 \mathrm{M}$ aqueous sodium nitrite $\left(\mathrm{NaNO}_{2}\right)$ solution was added and the total solution was degassed for 5 more min. The modification of the electrode surface was carried out via cyclic voltammetry with a scan rate of $50 \mathrm{mVs}^{-1}$ for 3 cycles between -0.5 and $0.8 \mathrm{~V}$ vs $\mathrm{Ag} / \mathrm{AgCl}$, starting from open circuit potential (OCP). After functionalization, the electrodes were thoroughly rinsed with deionised water, acetone and isopropanol (IPA), and subsequently dried under a stream of nitrogen. 4-aminophenethyl alcohol, $\mathrm{HCl}, \mathrm{NaNO}_{2}$, acetone and IPA were purchased from 
Sigma Aldrich (Belgium).

2.1.2 Electrochemical characterization. The functionalized electrodes were characterized by measuring the charge transfer properties. To this end, cyclic voltammetry measurements were performed in a solution of $0.01 \mathrm{M}$ iron(III) chloride $\left(\mathrm{FeCl}_{3}\right), 0.2 \mathrm{M}$ potassium chloride $(\mathrm{KCl})$ and $0.01 \mathrm{M} \mathrm{HCl}$ in deionised water, at a $\mathrm{pH}$ of $1.8 . \mathrm{FeCl}_{3} \cdot \mathrm{H}_{2} \mathrm{O}$ and $\mathrm{KCl}$ were purchased from Sigma Aldrich (Belgium).

\subsection{Oligonucleotide synthesis and characterization}

2.2.1 Oligonucleotide synthesis. To assess the suitability of electrodes with electrografted hydroxyl groups, oligonucleotide synthesis was performed on the modified electrodes in an Expedite 8909 synthesizer from Applied Biosystems (USA). After electrografting, pieces of ca. $5 \times 5 \mathrm{~mm}^{2}$ were cleaved from the gold electrode in order to fit the synthesis column of the DNA synthesizer. The oligonucleotide sequences were synthesized from 3' to 5', with the 3' end being attached to the functionalized electrode surface. The following sequences were synthesized:

$5^{\prime}-\mathrm{Cy} 3-3^{\prime}$

$5^{\prime}-\mathrm{Cy} 3-\mathrm{T}-3^{\prime}$

$5^{\prime}-\mathrm{Cy} 3-\mathrm{T}-\mathrm{T}-\mathrm{T}-3^{\prime}$

$5^{\prime}-\mathrm{Cy} 3-\mathrm{T}-\mathrm{T}-\mathrm{T}-\mathrm{T}-\mathrm{T}-\mathrm{T}-3^{\prime}$

$5^{\prime}-\mathrm{Cy} 3-{ }^{*}-3^{\prime}$

dT-CE phosphoramidite (referred to as "T") was ordered from Glen Research (USA). Cyanine-3-CE phosphoramidite (referred to as "Cy3") was ordered from Link Technologies Ltd (UK). The asterisk ("*") indicates a dummy cycle without any phosphoramidite present. An unmodified gold electrode was inserted during each synthesis run as a reference.

The reagents and timings for the synthesis cycle were used in correspondence to the protocol described in the DNA synthesizer manual. ${ }^{25}$ ) To ensure capping of non-reacted hydroxyl groups after coupling of the first phosphoramidite onto the grafted layer, the capping time of the first cycle was increased to $900 \mathrm{~s}$. The capping time for all subsequent cycles (phosphoramidite incorporation into the growing strand) was set to $180 \mathrm{~s}$.

2.2.2 Fluorescence characterization. To enable characterization of the oligonucleotide synthesis, a terminal Cy3-bearing phosphoramidite was incorporated. After synthesis, the fluorescence was verified using a Carl Zeiss LSM 780 confocal fluorescence microscope. For each image, the average fluorescence intensity was calculated. The standard deviation was used as a measure for the fluorescence intensity variation. 


\section{Results and discussion}

\subsection{Electrode functionalization and characterization}

Figure 2 shows the cyclic voltammogram (CV) of the electrografting of 4-aminophenethyl alcohol on a gold electrode. The first cycle shows a clear reduction peak at $\mathrm{E}_{\text {red }}=-0.040 \mathrm{~V}$, that practically disappears in the second and third scan. This is the typical behavior observed during the reduction of diazonium salts. The decrease of the reduction peak after the first scan indicates that an organic layer is grafted on top of the electrode surface, hindering electron transfer. ${ }^{26-30)}$ The blocking caused by deposition of species during the first scan results in a rapid decay of the current after the peak, rather than a diffusion-controlled decrease. $^{31)}$

The formation of an organic layer was also confirmed by recording cyclic voltammograms in a solution containing $\mathrm{FeCl}_{3}$ before and after electrografting. The resulting CVs are shown in Fig. 3. Before the grafting of 4-aminophenethyl alcohol, the CV recorded on the bare gold electrode clearly shows the characteristic reversible oxidation $\left(\mathrm{E}_{\mathrm{ox}}=0.59 \mathrm{~V}\right)$ and reduction $\left(\mathrm{E}_{\mathrm{red}}=0.42 \mathrm{~V}\right)$ peaks related to the iron ions in the solution. ${ }^{20,32-34)}$ After grafting, the same measurement was repeated. The resulting CV shows a decrease in oxidation and reduction peak currents, which indicates hindered charge transfer. This behavior is commonly interpreted as a proof of layer formation. ${ }^{32,33,35,36)}$ Electrografting can result in the formation of mono- or multilayers, depending on the modification procedure, the specific diazonium compound and the substrate material. The reactive radicals generated during reduction of the diazonium salt do not only bind to the electrode surface, but can also react with the ortho positions of already-grafted molecules. ${ }^{31,37)}$ This gives rise to tree-like multilayers. The thickness of these multilayers can be optimized by changing the electrografting parameters, such as the applied potential, the grafting time or the diazonium concentration. ${ }^{26,38)}$ Various techniques have been described to prevent multilayer formation, including the use of diazonium salts with sterically hindering groups ${ }^{39)}$ or sacrificial protection groups, ${ }^{33)}$ or via electrografting of calixarene molecules. ${ }^{35)}$

\subsection{Oligonucleotide synthesis and characterization}

Figure 4 shows the fluorescence results following a synthesis run with a Cy3-labeled phosphoramidite (5' - Cy3 - 3'). The first two electrodes are the modified ("Cy3") and the unmodified ("Ref1") electrode that were inserted into the synthesis column during the run, the third electrode ("Ref2") is an unmodified electrode that did not come into contact with any synthesis reagents. When comparing the electrodes that were present in the synthesizer, it is clear that the Cy3-labeled phosphoramidite could only bind to the electrode modified 
with 4-aminophenethyl alcohol. Non-specific adsorption of the fluorescent building block on the bare gold electrode ("Ref1") can be excluded, as the fluorescence intensity of the nonmodified witness electrode "Ref1" is comparable to that of the bare gold negative reference electrode "Ref2" that did not come into contact with the phosphoramidite. The surface irregularities observed in case of electrode "Cy3" can be assigned to scratches caused by the cleaving procedure, as they were also present in the brightfield images (data not shown).

To further evaluate the suitability of the electrografted layer as solid support for DNA synthesis, four different synthesis runs were performed on functionalized gold electrodes. In the first three runs, poly-T probes of different lengths (5' - Су3 - T - 3', 5' - Су3 - 3T - 3' and 5' - Cy3 - 6T - 3') were synthesized onto the functionalized electrodes. Each poly-T probe contained a terminal $\mathrm{Cy} 3$ phosphoramidite. In contrast, in the fourth run, a hydroxyl capping step was performed prior to introducing the Cy3-labeled phosphoramidite (5' - Cy3 - * - 3'). In standard phosphoramidite synthesis, this capping step is used to block any uncoupled 5 '-OH groups to prevent formation of incomplete oligonucleotides. ${ }^{22,23)}$ During all four synthesis runs, a negative reference electrode was included, that was not electrografted with 4-aminophenethyl alcohol, and therefore did not contain hydroxyl groups. Figure 5 shows the resulting fluorescence images after DNA synthesis.

The first three electrodes ("Cy3-T", "Cy3-3T" and "Cy3-6T"), containing poly-T oligonucleotides of different lengths with a terminal Cy3 group, clearly show a higher fluorescence intensity compared to the negative reference electrodes ("Ref1", "Ref2" and "Ref3", respectively). A higher fluorescence intensity can be observed for the longer oligo lengths. This can be explained by the varying distance of the Cy3 fluorophore from the metal surface. For deep sub-wavelength distances (i.e. one-tenth of the excitation wavelength), there is a strong non-linear dependence of the photon emission intensity. ${ }^{40)}$ Consequently, in case of longer probe length, the fluorescence experiences less quenching by the metal, since the fluorophore is further away from the electrode surface. ${ }^{41,42}$ ) The last electrode ("Cy3-Cap") shows a fluorescence intensity comparable to that of the negative reference electrodes, which proves that the capping step in the standard phosphoramidite cycle fully blocks all non-reacted hydroxyl groups, ensuring correct synthesis of each oligonucleotide.

\section{Conclusions}

We have demonstrated that electrografted gold electrodes can serve as a suitable solid support for oligonucleotide synthesis. The proposed method relies on the electrochemical reduction of 4-aminophenethyl alcohol, which introduces hydroxyl groups onto the metallic 
electrode surface. We have shown that these hydroxyl groups can bind the 3 ' end of a phosphoramidite moiety, as a starting point for the synthesis of the desired oligonucleotide sequence. Future work will focus on electrochemically induced deprotection, ${ }^{15)}$ enabling the synthesis of a custom sequence on each electrode. The demonstrated functionalization method offers an elegant approach to combine de novo DNA synthesis with electro-addressable electrodes of lithographic resolution.

\section{Acknowledgments}

The authors acknowledge the financial support from the Fund for Scientific Research Flanders (11ZE415N) (FWO). 


\section{References}

1) A. Adomas, G. Heller, A. Olson, J. Osborne, M. Karlsson, J. Nahalkova, L. Van Zyl, R. Sederhoff, J. Stenlid, R. Finlay, F.O. Asiegbu, Tree Physiol. 28, 885 (2008).

2) T.R. Golub, D.K. Slonim, P. Tamayo, C. Huard, M. Gaasenbeek, J.P. Mesirov, H. Coller, M.L. Loh, J.R. Downing, M.A. Caligiuri, C.D. Bloomfield, E.S. Lander, Science 286, 531 (1999).

3) L.J. van 't Veer, H. Dai, M.J. van de Vijver, Y.D. He, A.A. M. Hart, M. Mao, H.L. Peterse, K. van der Kooy, M.J. Marton, A.T. Witteveen, G.J. Schreiber, R.M. Kerkhoven, C. Roberts, P.S. Linsley, R. Bernards, S.H. Friend, Nature 415, 530 (2002).

4) S. Ramaswamy, P. Tamayo, R. Rifkin, S. Mukherjee, C.-H. Yeang, M. Angelo, C. Ladd, M. Reich, E. Latulippe, J.P. Mesirov, T. Poggio, W. Gerald, M. Loda, E.S. Lander, T.R. Golub, Proc. Natl Acad. Sci. U. S. A. 98, 15149 (2001).

5) D.R. Rhodes, J. Yu, K. Shanker, N. Deshpande, R. Varambally, D. Ghosh, T. Barrette, A. Pandey, A.M. Chinnaiyan, Proc. Natl Acad. Sci. U. S. A. 101, 9309 (2004).

6) J.G. Hacia, J.-B. Fan, O. Ryder, L. Jin, K. Edgemon, G. Ghandour, R.A. Mayer, B. Sun, L. Hsie, C.M. Robbins, L.C. Brody, D. Wang, E.S. Lander, R. Lipshutz, S.P.A. Fodor, F.S. Collins, Nat. Genet. 22, 164 (1999).

7) D. Wang, L. Coscoy, M. Zylberberg, P.C. Avila, H.A. Boushey, D. Ganem, J.L. DeRisi, Proc. Natl Acad. Sci. U. S. A. 99, 15687 (2002).

8) C. Conejero-Goldberg, E. Wang, C. Yi, T.E. Goldberg, L. Jones-Brando, F.M. Marincola, M.J. Webster, E.F. Torrey, Biotechniques 39, 741 (2005).

9) L. Mamanova, A.J. Coffey, C.E. Scott, I. Kozarewa, E.H. Turner, A. Kumar, E. Howard, J. Shendure, D.J. Turner, Nat. Methods 7, 111 (2010).

10) T.J. Albert, M.N. Molla, D.M. Muzny, L. Nazareth, D. Wheeler, X. Song, T.A. Richmond, C.M. Middle, M.J. Rodesch, C.J. Packard, G.M. Weinstock, R.A. Gibbs, Nat. Methods 4, 903 (2007).

11) V. Trevino, F. Falciani, H.A. Barrera-Saldaña, Mol. Med. 13, 527 (2007).

12) M.J. Heller, Annu. Rev. Biomed. Eng. 4, 129 (2002).

13) X. Gao, E. Gulari, X. Zhou, Biopolymers 73, 579 (2004).

14) A.R. Pike, L.H. Lie, R.A. Eagling, L.C. Ryder, S.N. Patole, B.A. Connolly, B.R. Horrocks, A. Houlton, Angew. Chem. Int. Edit. 41, 615 (2002).

15) K. Maurer, J. Cooper, M. Caraballo, J. Crye, D. Suciu, A. Ghindilis, J.A. Leonetti, W. Wang, F.M. Rossi, A.G. Stöver, C. Larson, H. Gao, K. Dill, A. McShea, PloS One 1, e34 (2006).

16) K. Maurer, J. Cooper, M. Strathmann, A. Gindilis, U.S. Patent No 10/992,252 (2004). 
17) A.J. Downard, Electroanalysis 12, 1085 (2000).

18) J. Pinson, F. Podvorica, Chem. Soc. Rev. 34, 429 (2005).

19) J.J. Gooding, Electroanalysis 20, 573 (2008).

20) K. Levrie, K. Jans, R. Vos, N. Ardakanian, N. Verellen, C. Van Hoof, L. Lagae, T. Stakenborg, Bioelectrochemistry 112, 61 (2016).

21) F. Barrière, A.J. Downard, J. Solid State Electrochem. 12, 1231 (2008).

22) D.J. Dellinger, J.R. Betley, T.K. Wyrzykiewicz, M.H. Caruthers, in Oligonucleotide Synthesis. Methods in Molecular Biology, ed. P. Herdewijn (Humana Press, New York, 2005), Vol. 288, Chap. 1.

23) R.A. Hughes, A.E. Miklos, A.D. Ellington, Methods Enzymol. 498, 277 (2011).

24) K. Levrie, K. Jans, G. Schepers, R. Vos, P. Van Dorpe, L. Lagae, C. Van Hoof, A. Van Aerschot, T. Stakenborg, Ext. Abstr. Solid State Devices and Materials, 2017, p. 945.

25) Expedite 8900 Nucleic Acid Synthesis System: User's Guide (PerSeptive Biosystems, Framingham, 1997), chapt. 7.

26) D. Bélanger and J. Pinson, Chem. Soc. Rev. 40, 3995 (2011).

27) A.J. Downard, Int. J. Nanotechnol. 6, 233 (2009).

28) S. Abdellaoui, B.C. Corgier, C.A. Mandon, B. Doumèche, C.A. Marquette, L.J. Blum, Electroanalysis 25, 671 (2013).

29) D. Evrard, F. Lambert, C. Policar, V. Balland, B. Limoges, Chem. Eur. J. 14, 9286 (2008).

30) J.C. Harper, R. Polsky, D.R. Wheeler, S.M. Brozik, Langmuir 24, 2206 (2008).

31) A. Laforgue, T. Addou, D. Bélanger, Langmuir 21, 6855 (2005).

32) K. Malmos, J. Iruthayaraj, S.U. Pedersen, K. Daasbjerg, J. Am. Chem. Soc 131, 13926 (2009).

33) Y.R. Leroux, H. Fei, J.-M. Noël, C. Roux, P. Hapiot, J. Am. Chem. Soc. 132, 14039 (2010).

34) M. Bengamra, A. Khlifi, N. Ktari, S. Mahouche-Chergui, B. Carbonnier, N. Fourati, R. Kalfat, M.M. Chehimi, Langmuir 31, 10717 (2015).

35) A. Mattiuzzi, I. Jabin, C. Mangeney, C. Roux, O. Reinaud, L. Santos, J.-F. Bergamini, P. Hapiot, C. Lagrost, Nat. Commun. 3, 1130 (2012).

36) G. Liu, M. Chockalingham, S.M. Khor, A.L. Gui, J.J. Gooding, Electroanalysis 22, 918 (2010).

37) J.K. Kariuki, M.T. McDermott, Langmuir 15, 6534 (1999).

38) A. Chira, B. Bucur, G.-L. Radu, Materials, 10, 235 (2017).

39) C. Combellas, F. Kanoufi, J. Pinson, F.I. Podvorica, J. Am. Chem. Soc. 130, 8576 (2008).

40) R.R. Chance, A. Prock, R. Silbey, Adv. Chem. Phys. 37, 65 (1978). 
41) Y. Cheng, T. Stakenborg, P. Van Dorpe, L. Lagae, M. Wang, H. Chen, G. Borghs, Anal. Chem. 83, 1307 (2011).

42) G. Schneider, G. Decher, N. Nerambourg, R. Praho, M.H.V. Werts, M. Blanchard-Desce, Nano Lett. 6, 530 (2006). 


\section{Figure Captions}

Fig. 1. (Black and white) Schematic drawing illustrating the proposed method for on-chip DNA synthesis. (a) Site-specific electrografting of 4-aminophenethyl alcohol on gold electrode. (b) Oligonucleotide synthesis on modified gold electrode using an automated DNA synthesizer (DNA depicted as wavy lines).

Fig. 2. (Black and white) Cyclic voltammogram of 4 -aminophenethyl alcohol $(5 \mathrm{mM})$ in a solution of $0.5 \mathrm{M} \mathrm{HCl} / 0.024 \mathrm{M} \mathrm{NaNO}_{2}$. Three cycles were performed at $50 \mathrm{mVs}^{-1}$.

Fig. 3. (Black and white) Cyclic voltammograms before and after electrografting of a gold electrode. $\mathrm{CV}$ measurements were performed at $50 \mathrm{mVs}^{-1}$ in a solution of $0.01 \mathrm{M} \mathrm{FeCl}_{3}$ / $0.2 \mathrm{M} \mathrm{KCl} / 0.01 \mathrm{M} \mathrm{HCl}$.

Fig. 4. (Black and white) Fluorescence intensity following synthesis using a Cy3-labeled phosphoramidite (depicted as star), with an electrografted electrode ("Cy3") and a non-electrografted electrode ("Ref1") in the synthesis column. A second non-electrografted electrode ("Ref2") that was not placed inside the synthesizer was used as a negative reference. The fluorescence microscopy images are shown in the inset.

Fig. 5. (Black and white) Fluorescence intensity of functionalized gold electrodes following DNA synthesis. Three different poly-T lengths with a terminal Cy3 group (depicted as star) were synthesized on electrodes 1 ("Cy3-T"), 2 ("Сy3-3T") and 3 ("Сy3-6T"). Electrode 4 ("Сy3-Cap") was first capped, after which a synthesis run with the Cy3 phosphoramidite was performed. The negative reference electrode in each synthesis run was a nonfunctionalized electrode. The fluorescence microscopy images are shown in the inset. 
(a) Electrode functionalization<smiles>Nc1ccc(CCO)cc1</smiles>

(b) On-chip DNA synthesis

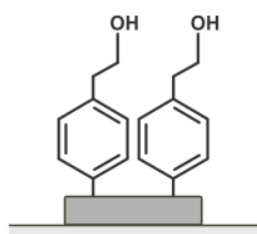

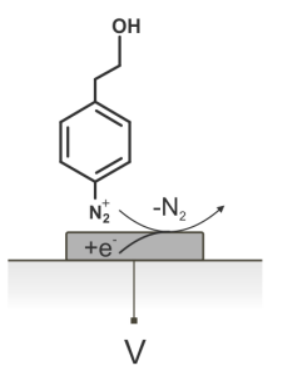

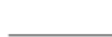
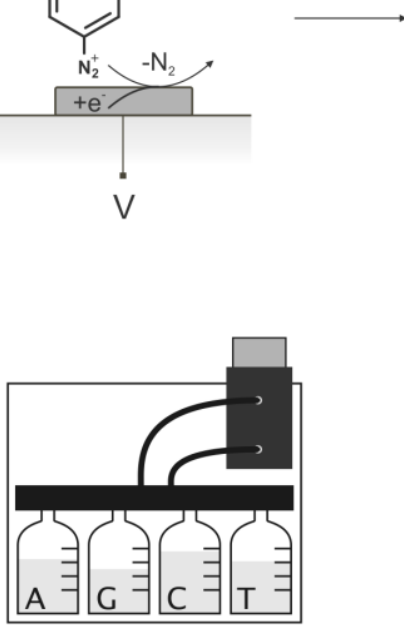
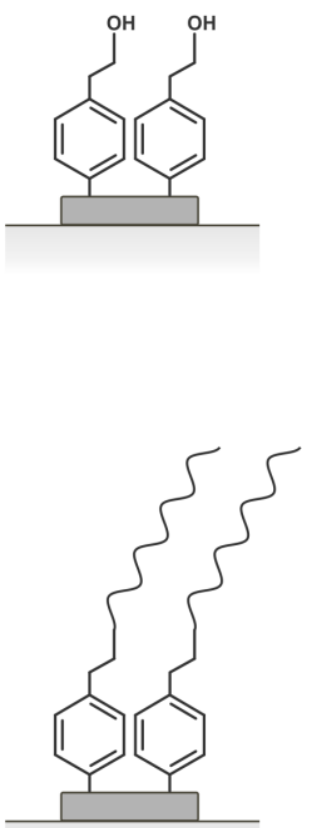

Fig. 1. (Black and white) 


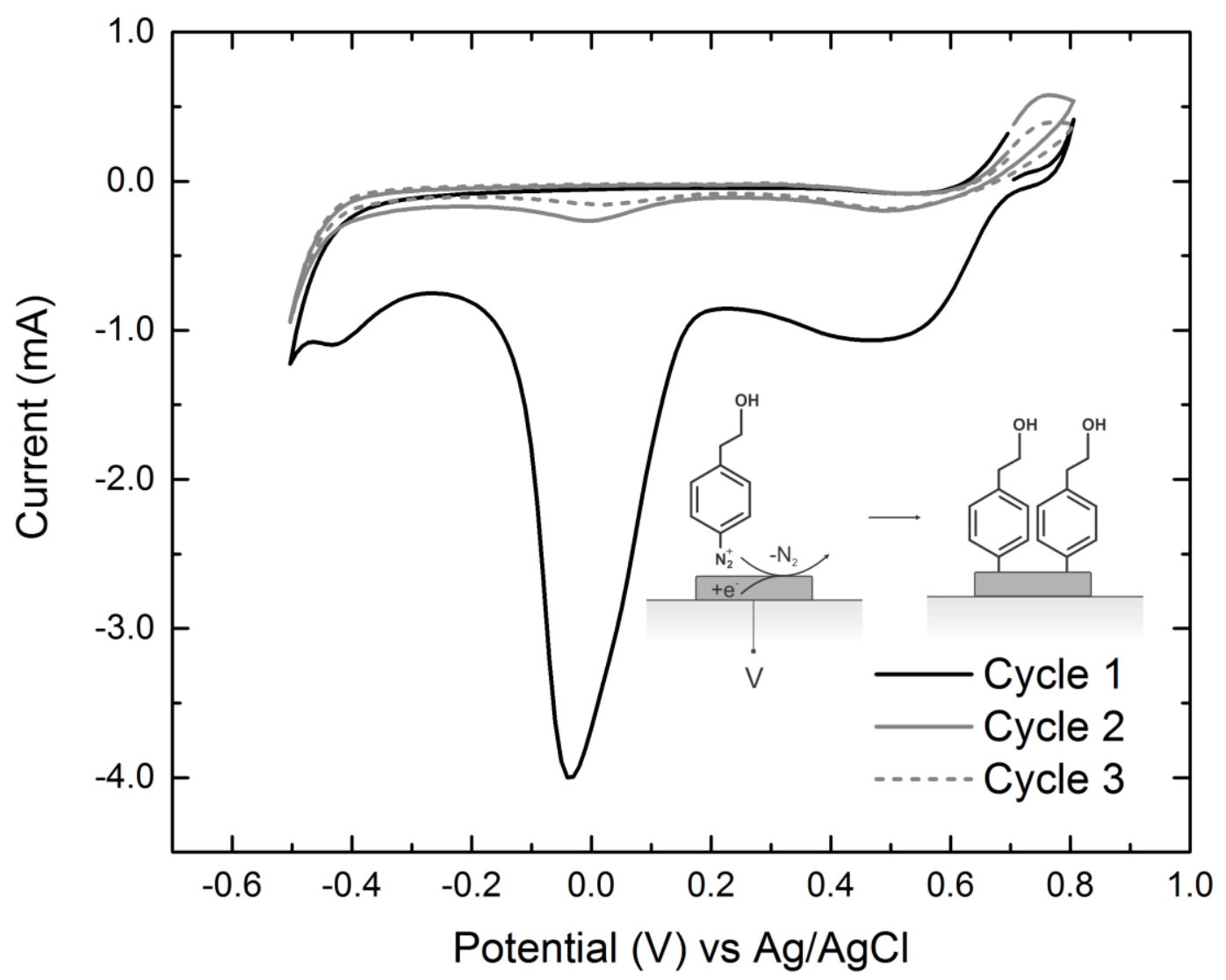

Fig. 2. (Black and white) 


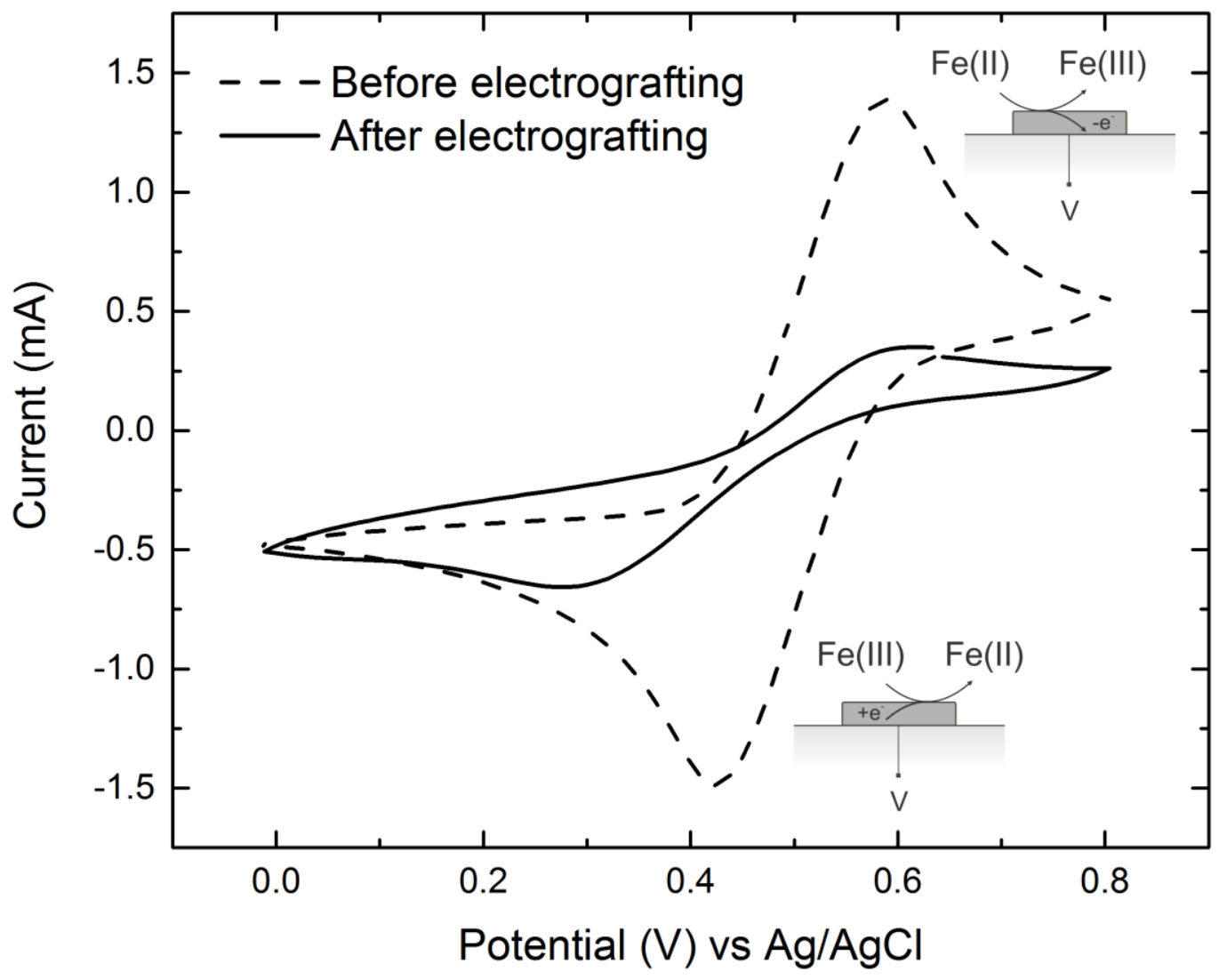

Fig. 3. (Black and white) 


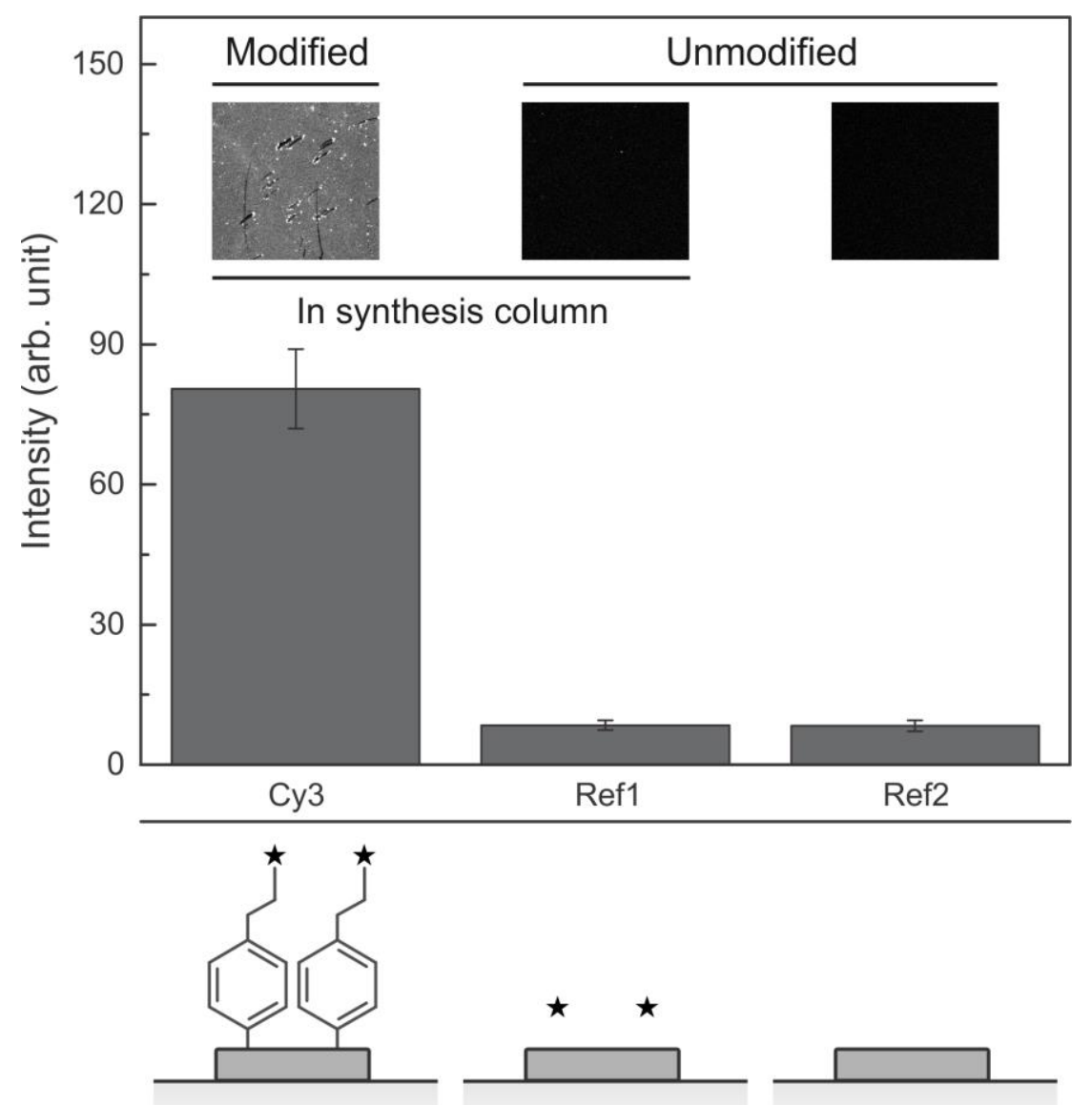

Fig. 4. (Black and white) 


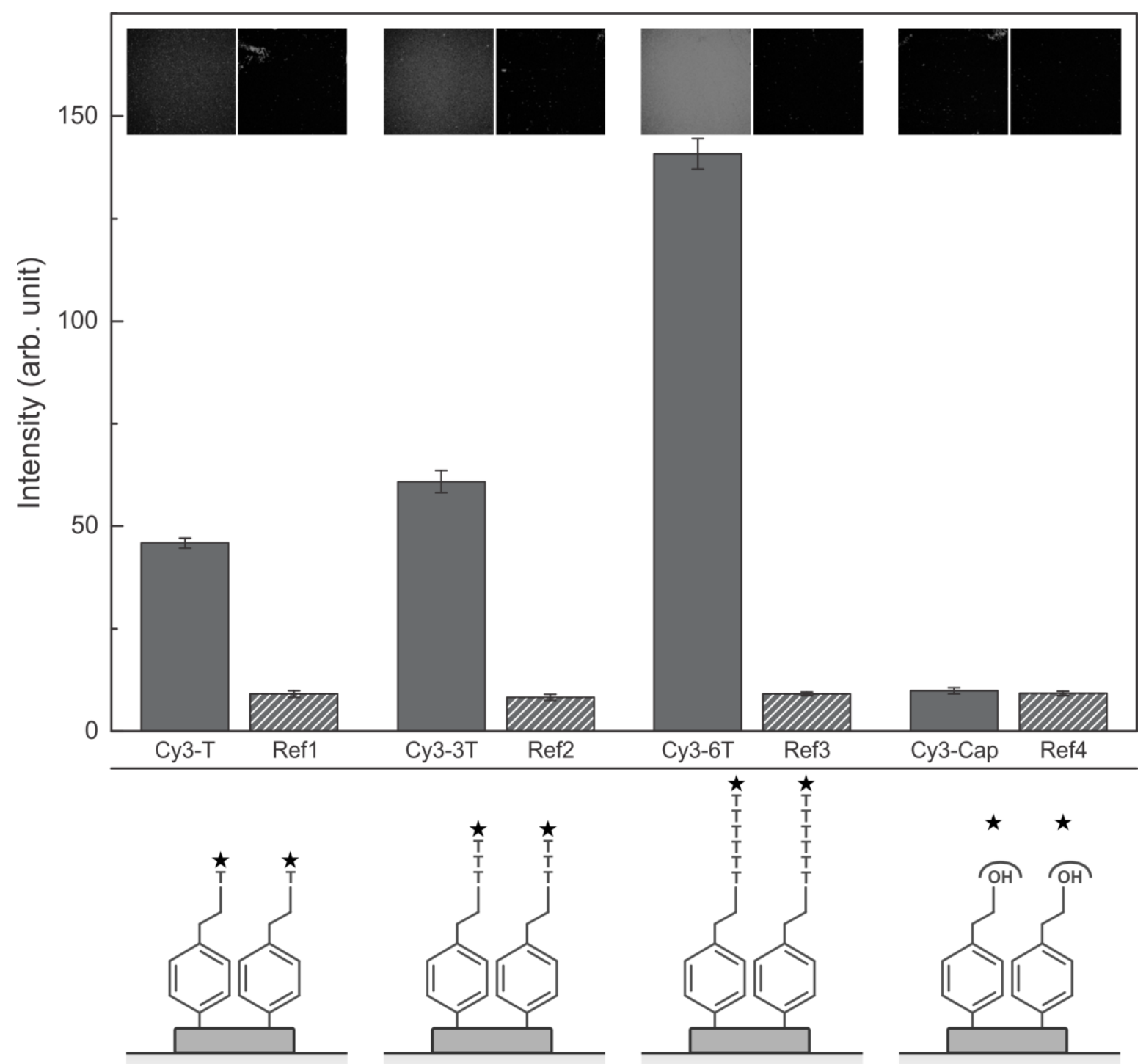

Fig. 5. (Black and white) 